\title{
Oscillatory Dynamics Underlying Perceptual Narrowing of Native Phoneme Mapping from 6 to 12 Months of Age
}

\author{
[CSilvia Ortiz-Mantilla, ${ }^{1}$ Jarmo A. Hämäläinen, ${ }^{2}$ TTeresa Realpe-Bonilla, ${ }^{1}$ and ${ }^{\circledR}$ April A. Benasich ${ }^{1}$ \\ ${ }^{1}$ Center for Molecular and Behavioral Neuroscience, Rutgers University Newark, Newark, New Jersey 07102, and ${ }^{2}$ Department of Psychology, University of \\ Jyväskylä, Jyväskylä 40014, Finland
}

During the first months of life, human infants process phonemic elements from all languages similarly. However, by 12 months of age, as language-specific phonemic maps are established, infants respond preferentially to their native language. This process, known as perceptual narrowing, supports neural representation and thus efficient processing of the distinctive phonemes within the sound environment. Although oscillatory mechanisms underlying processing of native and non-native phonemic contrasts were recently delineated in 6-month-old infants, the maturational trajectory of these mechanisms remained unclear. A group of typically developing infants born into monolingual English families, were followed from 6 to 12 months and presented with English and Spanish syllable contrasts varying in voice-onset time. Brain responses were recorded with high-density electroencephalogram, and sources of event-related potential generators identified at right and left auditory cortices at 6 and 12 months and also at frontal cortex at 6 months. Time-frequency analyses conducted at source level found variations in both $\theta$ and $\gamma$ ranges across age. Compared with 6-month-olds, 12-month-olds' responses to native phonemes showed smaller and faster phase synchronization and less spectral power in the $\theta$ range, and increases in left phase synchrony as well as induced high- $\gamma$ activity in both frontal and left auditory sources. These results demonstrate that infants become more automatized and efficient in processing their native language as they approach 12 months of age via the interplay between $\theta$ and $\gamma$ oscillations. We suggest that, while $\theta$ oscillations support syllable processing, $\gamma$ oscillations underlie phonemic perceptual narrowing, progressively favoring mapping of native over non-native language across the first year of life.

Key words: infant; oscillations; perceptual narrowing; phonemic mapping; source localization; time-frequency analyses

Significance Statement

During early language acquisition, typically developing infants gradually construct phonemic maps of their native language in auditory cortex. It is well known that, by 12 months of age, human infants move from universal discrimination of most linguistic phonemic contrasts to phonemic expertise in their native language. This perceptual narrowing occurs at the expense of the ability to process non-native phonemes. However, the neural mechanisms underlying this process are still poorly understood. Here we demonstrate that perceptual narrowing is, at least in part, accomplished by decreasing power and phase coherence in the $\theta$ range while increasing activity in high- $\gamma$ in left auditory cortex. Understanding the normative neural mechanisms that support early language acquisition is crucial to understanding and perhaps ameliorating developmental language disorders.

\section{Introduction}

To acquire language, typically, developing infants construct phonemic representations of the specific sounds of their native lan-

Received April 6, 2016; revised Sept. 8, 2016; accepted 0ct. 7, 2016.

Author contributions: S.O.-M., J.A.H., and A.A.B. designed research; S.O.-M. and T.R.-B. performed research; S.0.-M., J.A.H., and T.R.-B. analyzed data; S.O.-M. and A.A.B. wrote the paper.

This work was supported by National Science Foundation Grant SMA-1041755 to the Temporal Dynamics of Learning Center, an National Science Foundation Science of Learning Center, to A.A.B. and the Solomon Center for Neurodevelopmental Research.

The authors declare no competing financial interests.

Correspondence should be addressed to Dr. Silvia Ortiz-Mantilla, Center for Molecular and Behavioral Neuroscience, Rutgers University Newark, 197 University Avenue, Newark, NJ 07102. E-mail: sortizma@andromeda.rutgers.edu.

DOI:10.1523/JNEUROSCI.1162-16.2016

Copyright $\odot 2016$ the authors $\quad 0270-6474 / 16 / 3612095-11 \$ 15.00 / 0$ guage across auditory cortex. In the first months of life, human infants readily discriminate most phonemic contrasts across languages via detailed acoustic analysis. By the end of their first year, however, infants gradually narrow their perceptual abilities to become expert processors of native phonemic contrasts; that is, they evolve into automatized "linguistic" processors (Shafer et al., 2011; Strange, 2011), although they decline in their ability to discriminate non-native phonemic information (Werker and Tees, 2005; Gervain and Mehler, 2010; Kuhl, 2010). Phonemic perceptual narrowing, a developmental process that establishes preference for characteristic features of the infant's native language (Pons et al., 2009; Werker et al., 2012; Maurer and Werker, 2014; Gervain, 2015), occurs in a well-defined hierarchical progression. Initially, infants favor processing of suprasegmental 
prosodic features of their native language (Mehler et al., 1988; Hayashi et al., 2001; Jusczyk, 2002; Friederici et al., 2007), followed by preference for the characteristic information comprised in native vowels (Khul et al., 1992; Cheour et al., 1998; Shafer et al., 2011; Moon et al., 2013; Tsuji and Cristia, 2014); and finally, the focus is on the segmental sublexical elements contained in native consonants (Best et al., 1995; Rivera-Gaxiola et al., 2005; Tsao et al., 2006; Ortiz-Mantilla et al., 2013). Significant delays in the time course of phonemic narrowing (maintaining the ability to process non-native phonemes without establishing a clear native language preference) could negatively impact efficient language acquisition (Kuhl et al., 2005; Jansson-Verkasalo et al., 2010).

Phoneme recognition requires precise sensitivity to the specific spectrotemporal acoustic features that characterize each phoneme. One such feature is voice-onset time (VOT: time interval between the onset of the release burst and the onset of the voicing), which allows discrimination between stop consonants that share the same place of articulation (Lisker and Abramson, 1964). Human and animal studies have revealed evidence of cortical encoding of phonemic acoustic features in primary auditory cortex as neurons respond to the distinctive acoustic features that identify a given phoneme (Steinschneider et al., 2005; Mesgarani et al., 2008; Edwards et al., 2009; Leonard and Chang, 2014). The posterior superior temporal lobe has been proposed as the primary substrate where sound representation of speech is constructed (Hickok and Poeppel, 2000; DeWitt and Rauschecker, 2012) and may play a role in the early categorical phonetic analysis of speech stimuli (Blumstein et al., 2005; Chang et al., 2010). Recently, based on electrocorticographic (ECoG) recordings in epilepsy patients, the superior temporal gyrus (STG) (Mesgarani et al., 2014) and particularly, STG posterolateral region (PLSTG) (Steinschneider et al., 2011), were identified as the critical area responsible for the temporal representation of the acoustic features associated with VOT. Increases in event-related high- $\gamma$ power $(75-150 \mathrm{~Hz})$, the only frequency range examined, were seen in left and right PL-STG when consonantvowel syllables varying in VOT were passively presented.

In a previous study, we found selective enhancement of induced low- $\gamma$ oscillations in frontal cortex during discrimination of a native phonemic VOT contrast, suggesting that, at 6 months, the infant brain is already processing native phonemes differently from non-native ones (Ortiz-Mantilla et al., 2013). However, it is still not known whether, by the end of the first year of life when phonemic maps are thought to be firmly established, infants, like adults, show an increase in high- $\gamma$ power in auditory cortex, thus signaling neural representation of phonemic mapping and native language specialization at the phonemic level. As noted, it has been suggested that an increase in high- $\gamma$ power in PL-STG indicates acoustic mapping of VOT features. Consequently, we might expect that both native and non-native syllables would elicit a high- $\gamma$ oscillatory response. On the other hand, if enhancement of high- $\gamma$ power in PL-STG is a marker for "language-specific" phonemic mapping, we might anticipate that, by 12 months of age, high- $\gamma$ activity would be exclusively elicited by native syllables.

\section{Materials and Methods}

Participants. The present study includes a subset of 36 typically developing infants, born to monolingual English families that participated in a large developmental study. From this group, 29 (9 females) infants participated at 6 months of age, and 28 ( 10 females) at 12 months of age.
Data from the 6 month infants were previously reported (Ortiz-Mantilla et al., 2013), and the present study reports on the prospective, longitudinal follow-up of these infants at 12 months of age. Twenty-one infants (7 females) have good data at both age points. All infants had uneventful prenatal and perinatal circumstances and were born healthy, full-term (mean gestational age: 39.84 weeks, SD: 1.36 weeks), and at normal birth weight (mean: $3554.6 \mathrm{~g}, \mathrm{SD}: 409.4 \mathrm{~g}$ ) into middle to upper-middle socioeconomic class families (Hollingshead, 1975). Infants were recruited from urban and suburban communities in New Jersey and had no family history of specific language impairment, autism, hearing loss, no repeated episodes of otitis media, or other medical or neurological disorders. Parents received compensation for their time, and infants were given a toy after the visit. The study was conducted in accordance with the Declaration of Helsinki, and informed consent approved by our university's Human Subjects Institutional Review Board was obtained before inclusion in the study.

Procedure: event-related potentials (ERPs). Stimuli: Three consonantvowel (CV) syllables varying in VOT were used in this study. The standard stimulus (STD) was a CV syllable phonetically relevant in both English and Spanish, unaspirated voiceless /ta/ (VOT: $12 \mathrm{~ms}$ ) heard as "da" by native English speakers and heard as "ta" by native Spanish speakers. The native deviant (ND) syllable was voiceless aspirated/ta/ (VOT: $46 \mathrm{~ms}$ ) heard as "ta" by English speakers and the non-native deviant (NND) syllable was voicing-lead Spanish /da/ (VOT: - $24 \mathrm{~ms}$ ) heard as "da" by both Spanish and English speakers (the Spanish contrast $/ \mathrm{da} /-/ \mathrm{ta} /$ represent a single phonemic category in the English language and both syllables are perceived by English speakers as English /da/). Each CV syllable was 230-ms-long and had a fundamental frequency of 180 $\mathrm{Hz}$. The stimuli were presented in a passive oddball paradigm that contained 800 STD syllables, 100 ND syllables, and 100 NND syllables for a total of 1000 stimuli. The stimulus onset-to-onset interval was $930 \mathrm{~ms}$ (for a more detailed description of these stimuli and the paradigm used, see Rivera-Gaxiola et al., 2005, 2007, 2012; Ortiz-Mantilla et al., 2012, 2013). Auditory stimuli were matched for intensity and presented binaurally in a sound-attenuated free field environment at $69 \mathrm{~dB}$ SPL.

EEG recording and data processing. EEG/ERP recordings were acquired while participants were seated in their parent's lap, watching a silent movie or entertained with silent toys (for a more detailed description of the methods used, see Musacchia et al., 2015). EEG was recorded using a $62 \mathrm{Ag} / \mathrm{AgCl}$ channel EGI sensor net (Electrical Geodesics) with the vertex electrode $(\mathrm{Cz})$ used as the online reference, a sampling rate of $250 \mathrm{~Hz}$, and high/low pass filters between 0.1 and $100 \mathrm{~Hz}$. Eye blinks were removed from the raw data using Brain Electrical Source Analysis (BESA) software's automatic correction algorithm (principal component analysis method). ERPs were processed off-line with BESA software using a bandpass filter of $1-15 \mathrm{~Hz}$ and rereferenced to an average reference. For EEG segmentation, $300 \mathrm{~ms}$ prestimulus and $930 \mathrm{~ms}$ poststimulus time was used, and $100 \mathrm{~ms}$ before stimulus onset was defined as baseline. After segmentation, three types of epochs were available according to stimulus type (STD, ND, NND); epochs with signals exceeding $\pm 300 \mu \mathrm{V}$ from the baseline were excluded. To be included in ERP averaging, a minimum of $70 \%$ artifact-free epochs was required for each stimulus (6 months: average for STD: 78 trials [71-90], for ND: 80 trials [72-89], for NND: 79 trials [71-90]; 12 months: average for STD: 78 trials [72-86], for ND: 80 trials [74-89], for NND: 79 trials [71-86]). To ensure similar signal-tonoise ratio between responses to standard and deviant contrasts, only the standard epochs that preceded the ND were included in the averaged standard response.

MRI. Structural T-1weighted 3D SPGR images were acquired on a GE $1.5 \mathrm{~T}$ Echospeed scanner for a subset of nonsedated, naturally sleeping infants (for a detailed explanation of the scanning procedures, see Raschle et al., 2012). MRI brain templates for 6 and 12 months were created by affine transform of 19 ( 6 months) and 9 ( 12 months) MRI images into the MRI space of an infant with the median age of the sample and combined into an average image. The original individual and average (template) MRIs were processed with Brain Voyager QX software and imported into BESA Research 5.3 for source localization of the ERP generators. Age-appropriate parameters were calculated for thickness (6 months: skull: $1.5 \mathrm{~mm}$; scalp: $2.5 \mathrm{~mm}$; subarachnoid space: $1.7 \mathrm{~mm} ; 12$ 
months: skull: $2.0 \mathrm{~mm}$; scalp: $2.5 \mathrm{~mm}$; subarachnoid space: $1.5 \mathrm{~mm}$ ) and skull conductivity ( 6 months: $0.0581 ; 12$ months: 0.0527 ) of the infant structures to be used during source localization (for a detailed description of the technique used, see Hämäläinen et al., 2011; Ortiz-Mantilla et al., 2012).

Source localization of ERP generators. To gain a deeper understanding of the neural dynamics that support ERPs obtained using traditional EEG analyses, source localization techniques were applied to identify the neural generators of the ERP responses. Scalp surface EEG recordings are not informative as to where in the brain responses are generated, as each electrode location captures overlapping information and thus does not represent activity from neural tissue below any specific electrode (Ponton et al., 2002; Hoechstetter et al., 2004; Michel et al., 2004; CosandierRimélé et al., 2008). A dipole model based on activity recorded using a dense array of sensors (Michel et al., 2004) gives a more robust representation by providing maximal separation of the sources of activation from different brain regions that normally overlap at the scalp surface. Thus, modeling generators of the ERP responses allows identification of areas of activation (Hari and Salmelin, 1997) and, further, may reveal hidden sources of activation not always obvious with surface sensors (David et al., 2011). Generators of the ERP responses were investigated by mapping ERP data onto the individual or average MRI using BESA and Brain Voyager QX software programs (Scherg et al., 2010a). The standard electrode positions were fitted onto their corresponding MRI for 16 infants at 6 months and 12 infants at 12 months. Infants, for whom individual MRIs were not available, had the electrode positions fitted onto the ageappropriate MRI template. Peaks for responses to STD, ND, and NND were identified from the grand average and from the individual ERP waveforms at each age. Before conducting dipole modeling, ERP peak amplitudes were confirmed to be significantly different from zero baseline using one-sample $t$ tests $(p<0.001)$. Then, equivalent current dipole sources were fitted (Scherg and Von Cramon, 1985) using a 4-shell ellipsoidal head model, and a confirmatory distributed source model calculated using Classic LORETA Recursively Applied (CLARA) method (Hoechstetter et al., 2010); a time window of $\pm 20 \mathrm{~ms}$ around the selected peak was used for dipole fitting, which allowed the best signal-to-noise ratio. Peaks for each condition and source at each age were identified, and amplitude, latency, and source coordinates submitted to statistical analyses (for further description of the method, see Ortiz-Mantilla et al., 2012).

Time-frequency analyses. Spectrotemporal changes during perception of native and non-native stimuli were examined in source space. The raw 62-channel recording was processed as follows: a fixed spatial filter (source montage) from each individual's source model (created from the averaged ERP data) was applied to the corresponding raw data, thus transforming the ongoing EEG into a 3-channel source space. This montage separates activity from different brain regions (i.e., left auditory cortex [LAC], right auditory cortex [RAC], and frontal cortex at the level of the anterior cingulate cortex [ACC]). Next, using complex demodulation, each single trial was transformed into the time-frequency domain (for detailed information of this methodology, see Scherg et al., 2010b). To compare the 6 month with the 12 month data, parameters for timefrequency analysis were kept similar to those previously reported for the 6 month data (Ortiz-Mantilla et al., 2013) with two minor changes: (1) The noise level in infant ERPs is often higher than that typically observed in adult ERP recordings, thus introducing more error variance into source localization results. More noise was evident for the 12 month data compared with the 6 month, as older infants tend to be more active than at 6 months. To preserve as much of the frequency information as possible while at the same time controlling for low-frequency activity, a low cutoff of $0.5 \mathrm{~Hz}(90.5 \%$ of the data) and of $1 \mathrm{~Hz}(9.5 \%$ of the data) was applied to the raw EEG (Scherg et al., 2010b) at both ages. The $0.5 \mathrm{~Hz}$ high-pass filter was used for most children, but this was adjusted to $1 \mathrm{~Hz}$ in cases where prominent slow-wave activity was present. (2) As infants grow older, a developmental shift is seen toward greater power in higher frequencies and less power in lower frequencies (Koroleva et al., 2002; Marshall et al., 2002; Orekhova et al., 2006; Cragg et al., 2011). To examine an extended frequency range of the $\gamma$ band, a higher frequency range of $2-90 \mathrm{~Hz}$ was used at both ages, instead of the $2-50 \mathrm{~Hz}$ previously used
(Ortiz-Mantilla et al., 2013). A complex demodulation method with 1 -Hz-wide frequency bins and $50 \mathrm{~ms}$ time resolution, from -300 to 930 $\mathrm{ms}$ in the frequency range of $2-90 \mathrm{~Hz}$ was then used for decomposing the 6 and 12 month single-trial EEG data into time-frequency representations. Temporal spectral evolution (TSE) was used to examine eventrelated changes in amplitude (power) of the different frequency bands relative to the baseline (Tallon-Baudry et al., 1996; Hari et al., 1997; Tallon-Baudry and Bertrand, 1999). The TSE value is comprised of induced (random-phase/non-phase-locked) and evoked (phase-locked) changes in amplitude of oscillatory activity related to stimulus presentation. The intertrial phase locking (ITPL) value measures how consistently the phase at different frequency bands locks to stimulation presented across trials; a value of 0 indicates random phase across trials, and a value of 1 corresponds to perfect intertrial phase alignment (Tallon-Baudry et al., 1996; Tallon-Baudry and Bertrand, 1999). TSE and ITPL measurements were obtained at the three sources previously identified (i.e., LAC and RAC and frontal at the level of ACC), for each of the three stimuli (STD, ND, NND) that were presented at each age to the infants. The TSE and ITPL measures of each individual generated for each source and stimulus at each age were exported to MATLAB R2012a (The MathWorks) for plotting graphics across subjects.

Statistical analyses. The statistical analyses were conducted using BESA Statistics 1.0 (BESA) for permutation testing and cluster analysis and SPSS Statistics 21 (SPSS) for the repeated-measures ANOVA. The source strength and latency were examined separately using source $X$ stimulus $X$ age repeated-measures ANOVAs. Source coordinates ( $x$ : mediallateral; $y$ : anterior-posterior; and $z$ : superior-inferior) were examined separately for each direction also using repeated-measures ANOVAs. For time-frequency analysis, statistics were conducted in two steps (Kriegeskorte et al., 2009): First, we detected time-frequency regions with significant changes in the magnitude of amplitude (TSE) and phase coherence (ITPL) using BESA Statistics 1.0 software. BESA Statistics uses a parameter-free permutation testing on the basis of Student's $t$ test (Maris and Oostenveld, 2007). In this study, there were no "predefined" clusters as BESA Statistics 1.0 automatically identifies clusters in time and frequency that are significantly different between 2 conditions/stimuli. Results are considered corrected for multiple comparisons as only those clusters will be identified that have higher cluster values than $95 \%$ of all clusters derived by random permutation of data (a more detailed description of the methods can be found in BESA Statistics website: http://www.besa.de/products/besa-statistics/brochures/). The mean of each cluster was calculated, and then, the same cluster parameters were used to obtain information about the third condition. In this way, we were able to identify at each age, "data clusters of significance" in the time-frequency domain. Second, repeated-measures ANOVAs (Source $X$ Stimulus $\times$ Age), using the mean of each significant cluster, were conducted to examine age $X$ stimulus interactions in the sources. Post hoc tests were conducted when indicated to elucidate significant main effects. Greenhouse-Geisser correction was applied if the sphericity assumption was not met.

\section{Results}

\section{Source analyses}

At 6 and 12 months, ERP responses to STD, ND, and NND stimuli were characterized by a frontocentral-positive deflection $\sim 200 \mathrm{~ms}$ followed by a negative deflection at $\sim 400 \mathrm{~ms}$ (Fig. 1) similar to those described in other studies using the same paradigm (e.g., Rivera-Gaxiola et al., 2005, 2007). To examine perceptual processing of the different phonemes, sources of the first positive ERP response for each stimulus at each age were identified. At 6 months, we found that a 3-dipole model explained $\sim 96 \%$ of the variance (residual variance in the grand average for STD: $4.0 \%$, ND: $3.9 \%$, and NND: $3.0 \%$ ) with 2 dipoles located at LAC and RAC, close to the STG, and a mid-frontal dipole, placed at the level of ACC (Ortiz-Mantilla et al., 2013). At 12 months, ERP generators located at LAC and RAC explained 94\% of the variance (residual variance in the grand average for STD: $6.2 \%$, 
ND: 5.4\%, and NND: 5.3\%); however, no dipole could be modeled at the frontal level. A distributed source model (CLARA) confirmed sources of activation at each age (Fig. 2). The source waveforms at both ages were characterized by a positive deflection followed by a negative deflection (Fig. 3), and resembled the original ERP waveforms (Fig. 1). Means and SD of amplitude and latency of the positive source peaks can be found in Table 1.

The $2 \times 3 \times 2$ (Source [LAC, RAC] $\times$ Stimulus [ND, NND, STD] $\times$ Age $[6$ months, 12 months]) repeated-measures ANOVAs were conducted separately on the source latency and amplitude. As no source of activation was found at 12 months in the ACC, the ANOVA model only included LAC and RAC sources. The ANOVA for the latency of the positive response revealed a main effect of source $\left(F_{(1,20)}=16.402, p=0.001\right)$ with the right source having a shorter latency than the left; a main effect of stimulus in which the STD stimulus had shorter latency than the ND $\left(F_{(2,40)}\right.$ $=9.282, p=0.000$; post hoc pairwise comparisons: $\mathrm{STD} / \mathrm{ND}: p=$ $0.000)$ and a main effect of age $\left(F_{(1,20)}=51.772, p=0.000\right)$ with faster processing at 12 than at 6 months of age. Statistical analysis on the source amplitude also demonstrated a main effect of stimulus: the peak amplitude for the STD stimulus was smaller than for the $\mathrm{ND}\left(F_{(2,40)}=8.589, p=0.001\right.$; post hoc pairwise comparisons: STD/ND: $p=0.004)$. This result captures the same information as a "mismatch response" and suggests that at both ages infants favor discrimination of the native contrast.

Differences in source locations across age were examined individually by $2 \times 3 \times 2$ (Source [LAC, RAC] $\times$ Stimulus [ND, NND, STD] $\times$ Age [ 6 months, 12 months]) ANOVAs for the $x, y$, and $z$ coordinates. A main effect of age $\left(F_{(1,20)}=8.183, p=0.01\right)$ and a main effect of source $\left(F_{(1,20)}=6.683, p=0.018\right)$ were found for the $x$ and $z$ coordinates, respectively. At 12 months, sources were more medially located compared with the 6 month sources; moreover, the sources in LAC were more inferior compared with the RAC sources. No significant differences were found for the $y$ coordinate.

\section{Time-frequency analyses}

Cluster analyses in the 2-50 Hz frequency range

Clusters of significance in the $2-50 \mathrm{~Hz}$ frequency range were identified through permutation testing and cluster analyses were conducted between ND and STD in the 6 month data. The following clusters were found: (1) For TSE in the $\theta$ range, a significant cluster was identified from 4 to $6 \mathrm{~Hz}$ between 100 and 400 ms, showing enhanced activity for the ND compared with the STD in the LAC ( $p=0.03)$; (2) for TSE in the low $\gamma$ range, a significant cluster was found from 30 to $34 \mathrm{~Hz}$ between 100 and $400 \mathrm{~ms}$, which showed more power elicited for ND than for STD in the ACC ( $p=0.018)$; and (3) for ITPL in the $\delta$ - $\theta$ range, a significant cluster found from 2 to $6 \mathrm{~Hz}$ between 0 and $400 \mathrm{~ms}$ revealed larger phase coherence for ND than for STD in the LAC $(p=0.013)$, as well as in ACC $(p=0.02)$. The mean of each cluster was calculated and then, the same cluster parameters were used to obtain information about the third condition (NND) for the 6 months.

Longitudinal analyses in the 2-50 Hz frequency range To allow comparison of the 6 and 12 month time-frequency data, a third fixed dipole, using the frontal location coordinates iden-
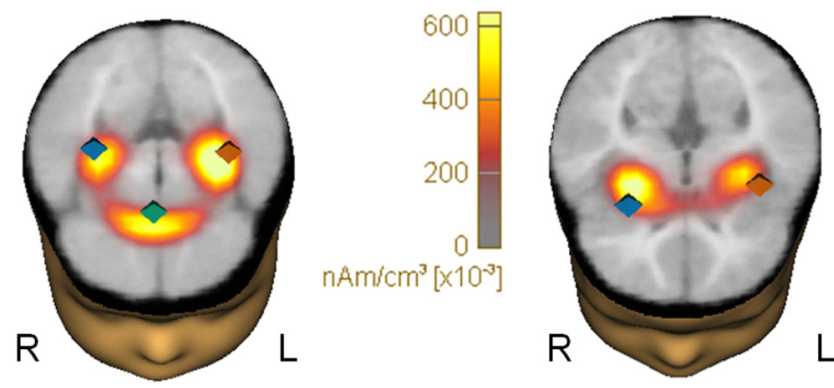

Figure 2. Source localization of the ERP generators is shown for the positive peak of the ND response, on the left for 6 months, and right for 12 months. Discrete equivalent current dipole and distributed $C L A R A$ solutions converged at left ( $L$; red) and right ( $R$; blue), auditory sources at both ages and at the frontal (green) ACC source at 6 months. No source of activation in the ACC was found at 12 months. Magnitude of CLARA activation is given in nanoampere meters by cubic centimeter $\mathrm{nAm} / \mathrm{cm}^{3}\left[\times 10^{-3}\right]$.

tified at 6 months, was added to the 12 month model. To investigate changes across development, the cluster parameters (TSE $\theta$, TSE low- $\gamma$, and ITPL $\theta$ ) identified in the 6 month data were applied to the 12 month data for all three conditions (ND, NND, STD). Stimulus $\times$ age interactions for amplitude (TSE) and phase synchrony (ITPL) were examined in source space using a repeated-measures ANOVA.

\section{TSE $\theta$}

A $3 \times 3 \times 2$ (Stimulus [ND, NND, STD] $\times$ Source [LAC, RAC, ACC] $\times$ Age [6 months, 12 months]) repeated-measures ANOVA was conducted on the mean of a cluster found between 100 and $400 \mathrm{~ms}$ in the $4-6 \mathrm{~Hz}$ frequency range (Fig. 4). Results showed a main effect of source: $\left(F_{(1.57,31.46)}=9.886, p=0.001\right.$; post hoc pairwise comparisons: LAC/RAC: $p=0.001$; LAC/ACC: $p=0.001)$ with larger power shown at the LAC source compared with the RAC and ACC sources, and a main effect of age: $\left(F_{(1,20)}\right.$ $=5.383, p=0.031)$ with larger power elicited at 6 compared with 12 months.

TSE low- $\gamma$

At 6 , but not at 12 , months of age, a frontal/ACC cluster of increased oscillatory activity in the low- $\gamma$ frequency range (100$400 \mathrm{~ms}, 30-34 \mathrm{~Hz}$ ) was found for ND (Fig. 5). A $3 \times 2$ (stimulus [ND, NND, STD] $\times$ age [ 6 months, 12 months]) repeatedmeasures ANOVA showed a stimulus by age interaction $\left(F_{(2,40)}=3.66, p=0.035\right)$ where larger power was seen at 6 than at 12 months for the ND, whereas no difference was found for the NND and STD stimuli across age.

ITPL $\theta$

An early increase in phase alignment was found in the $\delta$ - $\theta$ frequency band ( 0 and $400 \mathrm{~ms}, 2-6 \mathrm{~Hz})$. A $3 \times 3 \times 2$ (Stimulus [ND, 


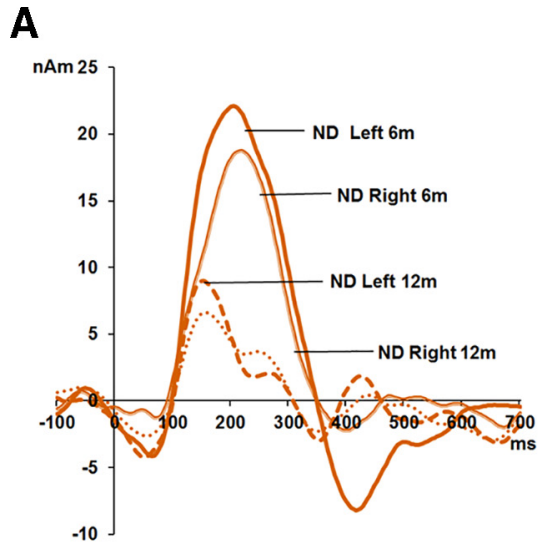

Native Deviant
B

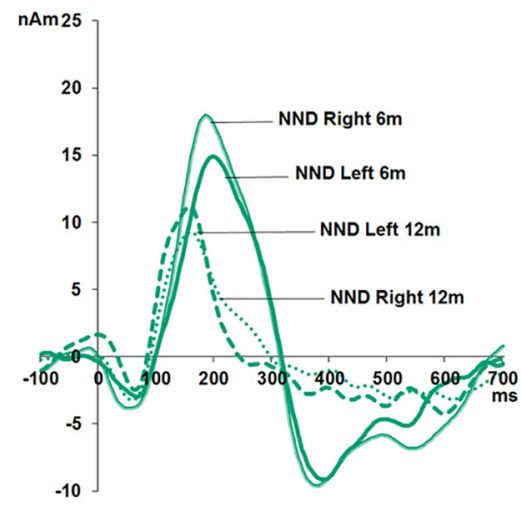

Non-native Deviant
C

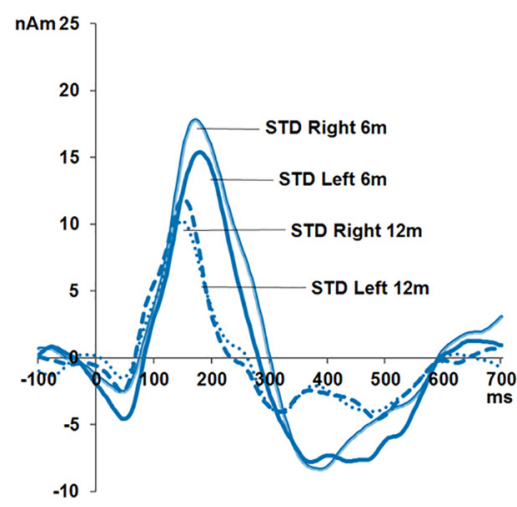

Standard

Figure 3. Grand average source waveforms of the responses to ND ( $\boldsymbol{A}$; red), NND ( $\boldsymbol{B}$; green), and STD ( $\boldsymbol{C}$; blue) are shown at the LAC as a thick solid line at 6 months and a thick dotted line at 12 months. For the RAC, a thin solid line indicates 6 month data and a thin dotted line indicates 12 month data. Positivity is plotted up; amplitude of the source dipole moment is given in nanoampere meters (nAm) and latency in milliseconds (ms).

Table 1. Amplitude and latency of the positive peak in response to the ND, NND, and STD stimuli based on individual source analyses ${ }^{a}$

\begin{tabular}{llllll}
\hline & \multicolumn{3}{l}{6 months } & & \multicolumn{2}{l}{12 months } \\
\cline { 2 - 3 } \cline { 6 - 6 } & Amplitude (nAm) & Latency (ms) & & Amplitude (nAm) & Latency (ms) \\
\hline ND LAC & $31.36(14.9)$ & $218(37.5)$ & & $29.54(20.4)$ & $159(28.5)$ \\
ND RAC & $33.19(12.4)$ & $206(24.5)$ & & $25.52(13.4)$ & $157(32.3)$ \\
ND ACC & $20.01(7.5)$ & $188(48.6)$ & & - & - \\
NND LAC & $30.06(10.7)$ & $206(29.0)$ & & $24.68(13.2)$ & $156(26.9)$ \\
NND RAC & $28.31(10.9)$ & $196(34.9)$ & & $23.64(10.9)$ & $148(19.6)$ \\
NND ACC & $23.85(13.5)$ & $191(40.5)$ & & - & - \\
STD LAC & $23.60(10.8)$ & $190(24.2)$ & & $23.08(12.9)$ & $149(14.6)$ \\
STD RAC & $27.58(13.6)$ & $182(23.6)$ & & $19.14(7.3)$ & $149(16.1)$ \\
STD ACC & $14.82(5.5)$ & $171(27.9)$ & - & - \\
\hline
\end{tabular}

${ }^{a}$ Data are mean (SD)

NND, STD] $\times$ Source [LAC, RAC, ACC] $\times$ Age $[6$ months, 12 months]) repeated-measures ANOVA revealed a source $X$ age interaction $\left(F_{(2,40)}=6.468, p=0.004\right)$. Theta phase coherence was larger at both LAC and RAC sources at 6 months compared with 12 months, whereas at the ACC source no change was seen across age (Fig. 6). In addition, a main effect of stimulus was found with larger phase coherence for ND than for $\operatorname{STD}\left(F_{(2,40)}=\right.$ 4.067, $p=0.025$; post hoc pairwise comparisons: ND/STD: $p=$ $0.007)$. Larger ITPL for ND than for STD could suggest that the mismatch discrimination response is supported by phase synchrony of $\theta$ oscillations.

Close examination of the ITPL $\theta$ plots suggested longer phase synchronization at 6 than at 12 months, particularly in LAC and RAC sources (Fig. 6). To explore further this developmental timing effect, we kept the same spectral range $(2-6 \mathrm{~Hz})$ but divided the time range into two nonoverlapping time-windows (TWs): TW1 from 0 to $200 \mathrm{~ms}$, and TW2 from 250 to $400 \mathrm{~ms}$. A $2 \times 2 \times$ $2 \times 2$ (Stimulus [ND, NND] $\times$ Source [LAC, RAC] $\times$ Age $[6$ months, 12 months] $\times$ TW [TW1, TW2]) repeated-measures ANOVA conducted on the mean of the clusters revealed an age $X$ TW interaction $\left(F_{(1,20)}=12.813, p=0.002\right)$. In general, larger ITPL was found at 6 compared with 12 months in both TWs. However, whereas at 6 months larger intertrial phase coherence was found at TW2 compared with TW1, at 12 months, larger ITPL was found in TW1 compared with TW2 (Fig. 7).

\section{Cluster analyses in the $\mathbf{5 0 - 9 0 ~} \mathrm{Hz}$ frequency range}

As high- $\gamma$ power has been suggested to index encoding of VOT features of native phonemes, and in accord with the known perceptual narrowing trajectory, both native phonemes (STD and ND) are expected to already be mapped by 12 months of age. Therefore, clusters of significance in the sources were investigated at 12 months in the $50-90 \mathrm{~Hz}$ frequency range using the ND and NND stimuli. The following clusters were found: (1) A significant TSE cluster was found in the high- $\gamma$ range $(>70 \mathrm{~Hz})$, from 70 to $77 \mathrm{~Hz}$ between 0 and $800 \mathrm{~ms}$ with the ND showing more frontal power than the NND ( $p=$ 0.016 ); and (2) for ITPL in the $\gamma$ range, a cluster was identified from 57 to $63 \mathrm{~Hz}$ between 50 and $300 \mathrm{~ms}$, which showed larger phase coherence for the ND compared with the NND in the LAC $(p=0.048)$. Parameters of the 12 month TSE high- $\gamma$ and ITPL $\gamma$ clusters were used to obtain information about the third condition at 12 months (STD).

\section{Longitudinal analyses in the 50-90 Hz frequency range}

To investigate changes across development, the same cluster parameters (TSE high- $\gamma$, and ITPL $\gamma$ ) identified in the 12 month data were applied to the 6 month data in all three conditions (ND, NND, STD). Stimulus $\times$ age interactions for amplitude (TSE), and phase synchrony (ITPL) were examined in source space using a repeated-measures ANOVA.

\section{TSE high- $\gamma(>70 \mathrm{~Hz})$}

A long burst of high- $\gamma$ oscillatory activity (70-77 $\mathrm{Hz}$ range, 0-800 ms) was elicited at 12 months (Fig. 8) for both native conditions (ND and STD). A $3 \times 3 \times 2$ (Stimulus [ND, NND, STD] $\times$ Source [LAC, RAC, ACC] $\times$ Age [6 months, 12 months]) repeated-measures ANOVA revealed a stimulus $X$ source $\times$ age interaction $\left(F_{(4,80)}=2.918, p=0.026\right)$. Compared with 6 months, 12 month ND and STD elicited larger $\gamma$ power in LAC and ACC sources than in the RAC source, whereas the NND showed the lowest amount of $\gamma$ power in the three sources at both ages.

\section{ITPL $\gamma$}

At 12 months, a significant increase in phase coherence was seen in the $\gamma$ band from 57 to $63 \mathrm{~Hz}$ between 50 and $300 \mathrm{~ms}$. A $3 \times 3 \times 2$ (Stimulus [ND, NND, STD] $\times$ Source [LAC, RAC, ACC $] \times$ Age $[6$ months, 12 months]) repeated-measures 
A
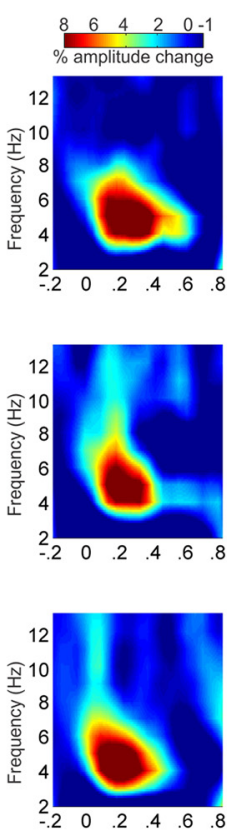

Figure 4. TSE grand average plots showing power for low-frequency oscillations in the $\theta$ range at LAC and RAC and at frontal at the level of the ACC. The TSE for 6-month-olds is shown on the left $(\boldsymbol{A})$ and for 12 -month-olds on the right $(\boldsymbol{B})$. Top row represents TSE for ND. Middle row represents TSE for NND. Bottom row represents power elicited by the STD. Time is shown in seconds (S) on the $x$-axis and frequency in $\mathrm{Hz}$ on the $y$-axis.

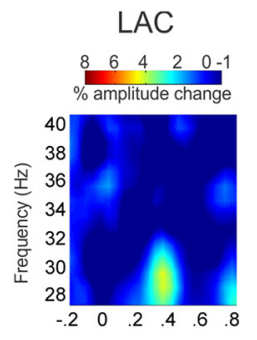

ACC
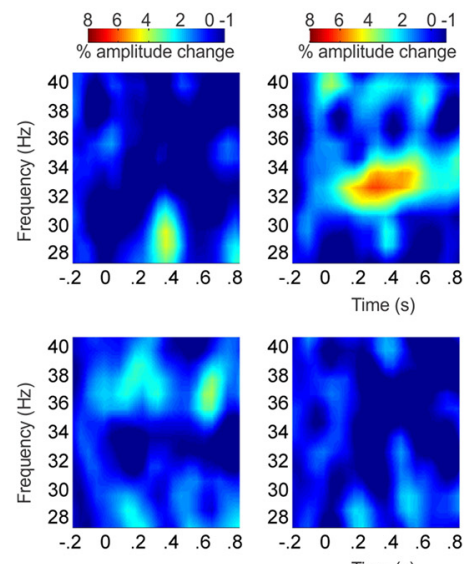

Time (s)

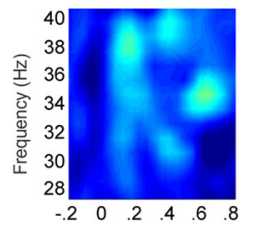

ACC



Time (s)
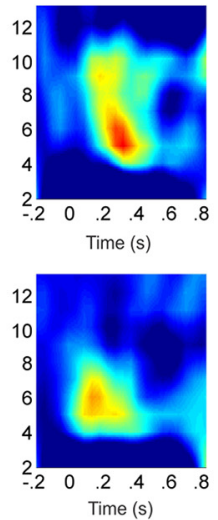

RAC


B
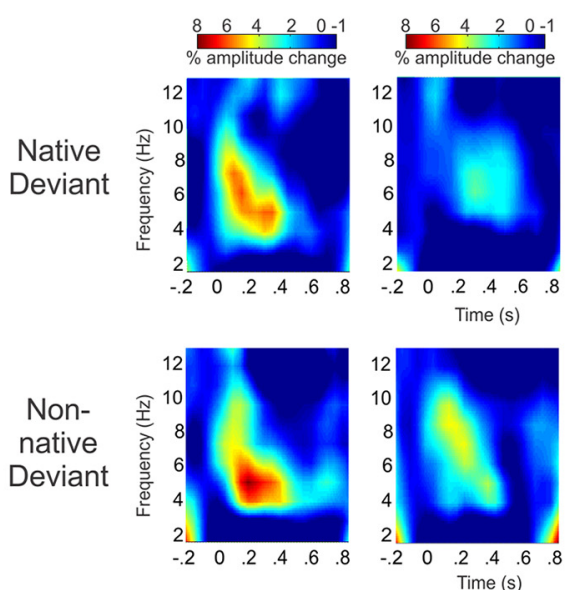

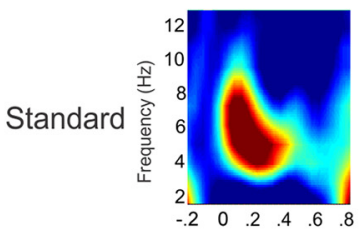

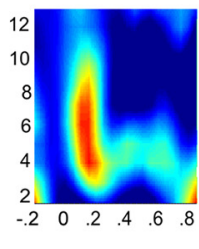

ACC

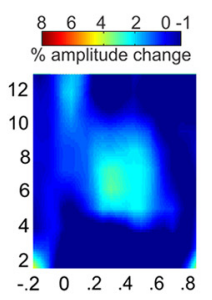

Time (s)

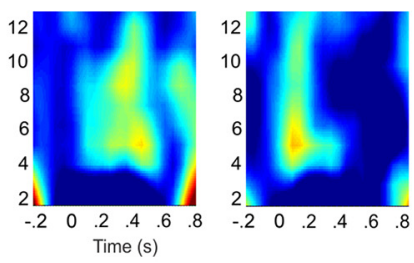

RAC

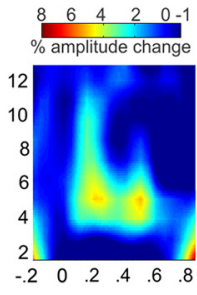

RAC
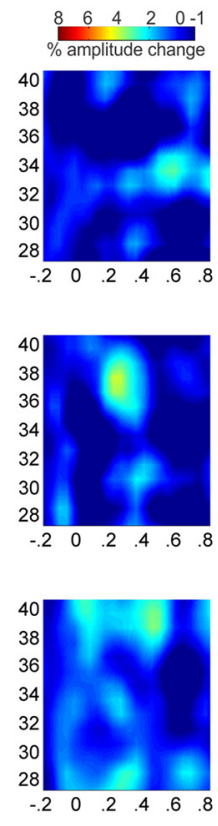

LAC

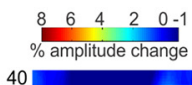

Native Deviant
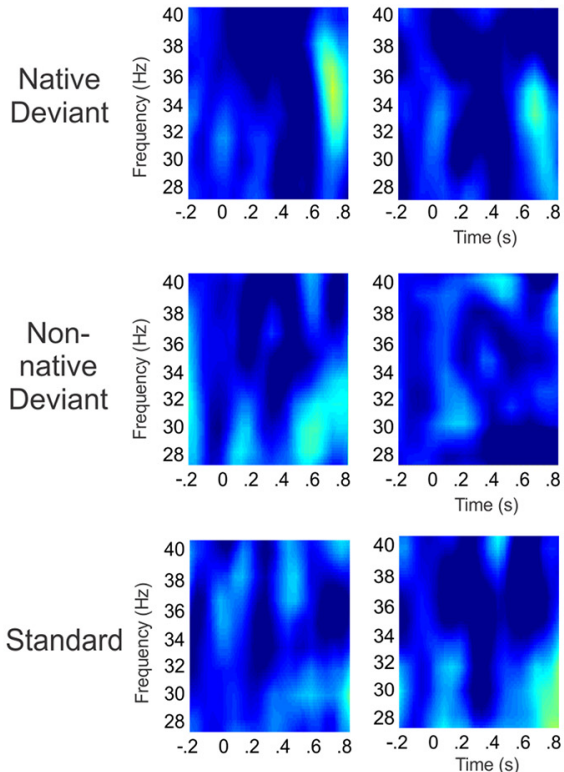

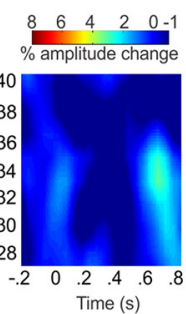

Time (s)

ACC

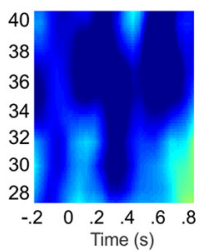

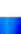

\section{.}
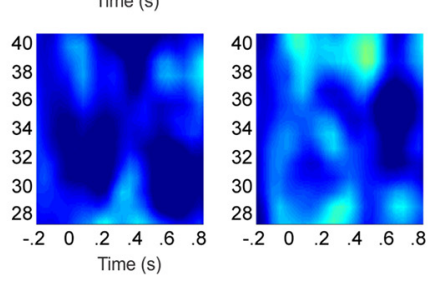

Figure 5. TSE grand average plots illustrating enhanced oscillatory activity in the low- $\gamma$ range at LAC and RAC and in frontal cortex at the level of ACC. Top row represents TSE for ND. Middle row represents TSE for NND. Bottom row represents power elicited by the STD. At 6 months of age, low- $\gamma$ activation is particularly evident for the ND stimulus in the ACC (second plot in the first row). The TSE for 6-month-olds is shown on the left $(\boldsymbol{A})$ and for 12-month-olds on the right $(\boldsymbol{B})$. Time is shown in seconds (s) on the $x$-axis and frequency on Hz on the $y$-axis.

ANOVA revealed a main effect of stimulus $\left(F_{(2,40)}=3.397\right.$ $p=0.043$; post hoc pairwise comparisons: ND/NND, $p=$ 0.031; ND/STD, $p=0.027$ ) with larger phase coherence shown for the ND stimulus compared with the NND and STD stimuli.

\section{Discussion}

Becoming an expert processor of native language is a developmental process mediated by the interplay between maturation and experience as reflected in neuroplastic changes in the neuro- 
A
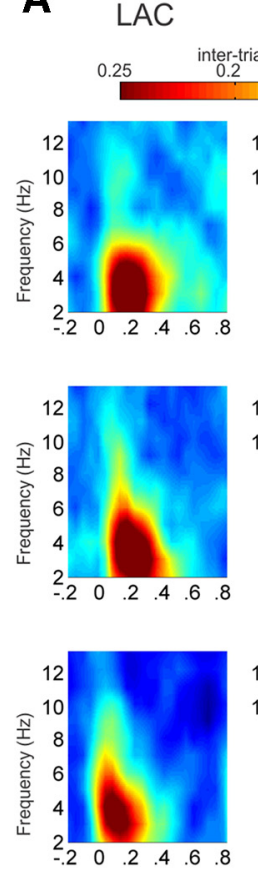

ACC

RAC
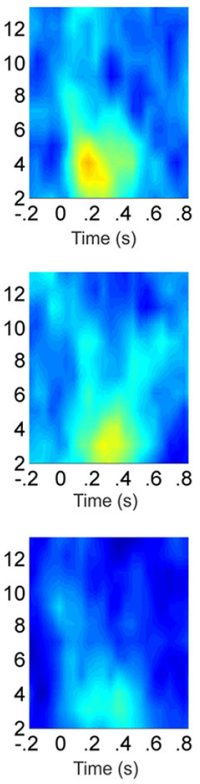
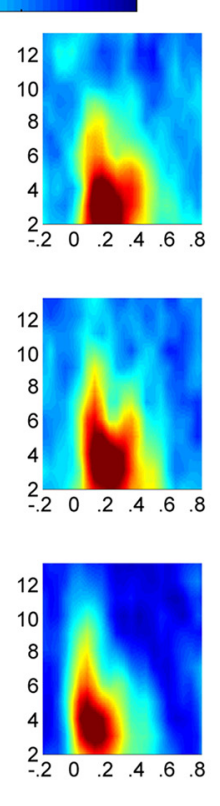

B

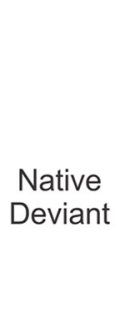

Non-

native

Deviant

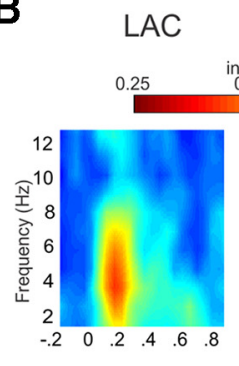

ACC

RAC
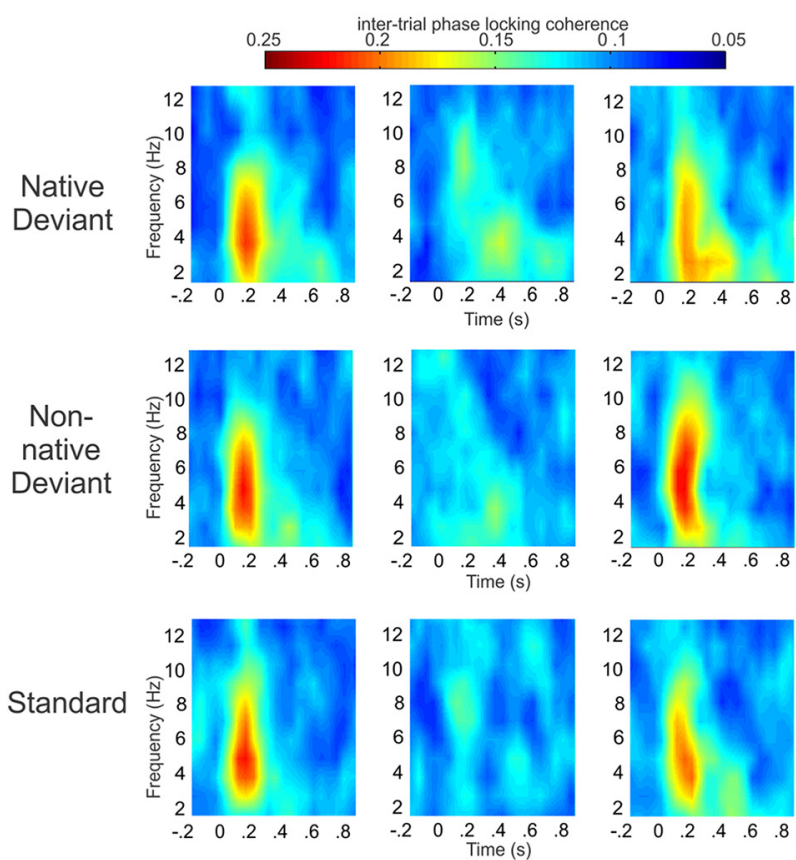

Figure 6. Grand average plots showing ITPL of low-frequency oscillations in the $\delta$ - $\theta$ range at LAC and RAC and at ACC. The ITPL for 6 months is shown on the left ( $\boldsymbol{A}$ ) and for 12 months is shown on the right ( $\boldsymbol{B})$. Top row represents ITPL for ND. Middle row represents ITPL for NND. Bottom row represents ITPL elicited by the STD. Time is shown in seconds (s) on the $x$-axis and frequency in Hz on the $y$-axis.

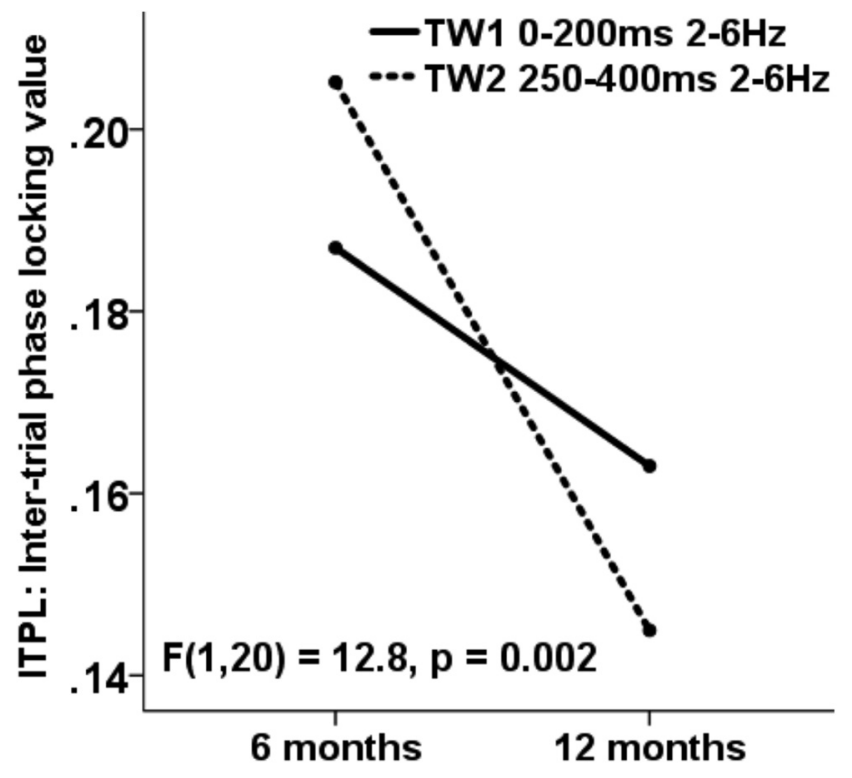

Figure 7. ITPL in the $\delta$ - $\theta$ range, showing infants' increase in speed of processing as a function of age. Age in months is shown on the $x$-axis and ITPL value on the $y$-axis. Specifically, there was a larger ITPL value at 6 months compared with 12 months in both TWs. However, an age $X$ TW interaction showed that 6 month ITPL was larger in TW2 (TW2: 2-6 Hz, $250-400 \mathrm{~ms}$; dashed line) compared with TW1 (2-6 Hz, $0-200 \mathrm{~ms}$; solid line), whereas 12 month ITPL was larger in TW1 compared with TW2.

nal networks that support acoustic mapping (Buonomano and Merzenich, 1998). In this study, we examined the neural dynamics underlying infant processing of native and non-native phonemic contrasts at 6 and 12 months of age. We found, across age, that the response to native and non-native syllables is characterized by a general decrease in the magnitude of power elicited in lower frequency ranges accompanied by widespread increases in high- $\gamma$ power as seen in LAC and frontal areas at 12 months of age. Our results align with studies reporting that, over development, oscillatory activity at lower frequencies gradually shifts to higher-frequency bands (Koroleva et al., 2002; Marshall et al., 2002; Orekhova et al., 2006; Cragg et al., 2011). High- $\gamma$ power in auditory cortex is thought to index mapping of segmental/phonemic information (Steinschneider et al., 2011). Hence, our finding of high- $\gamma$ power in LAC exclusively for native phonemes strongly supports the view that, by the end of the first year, infants have narrowed their perceptual abilities and made significant progress toward mapping the distinctive characteristics of their surrounding linguistic environment. Paralleling these changes in power, less $\theta$-phase alignment was seen at 12 than at 6 months. Furthermore, we found that phase locking in the $\theta$ range persisted over a shorter interval in older compared with younger infants, suggesting more rapid processing of syllabic information with age, particularly for discrimination of the ND stimulus. Finally, in the $\gamma$ range, a significant increase in intertrial phase coherence in the LAC marked preferential processing of the ND over NND.

\section{Role of $\boldsymbol{\theta}$ and $\boldsymbol{\gamma}$ band activity}

It is thought that low-frequency oscillations capture the activity of connected neuronal populations and may be involved in information transfer among brain areas (Wang et al., 2005; Wang, 2010; Saby and Marshall, 2012). Theta oscillations are important for perceptual and cognitive functions, such as spatial navigation and declarative and episodic memory processes (Sauseng and Klimesch, 2008; Wang, 2010; Musacchia et al., 2013) and have been proposed as the neural mechanism subserving stimulus discrimination (Ko et al., 2012; Jin et al., 2014). On the other hand, $\gamma$ oscillations may represent synchronized activity of local neuronal populations during sensory and cognitive processes (Ward, 
A

LAC
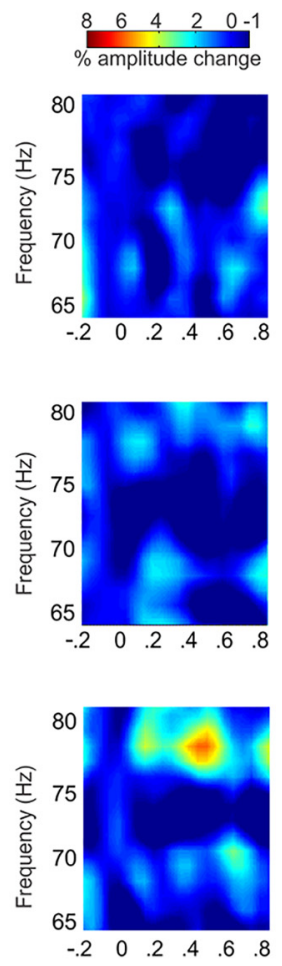

ACC
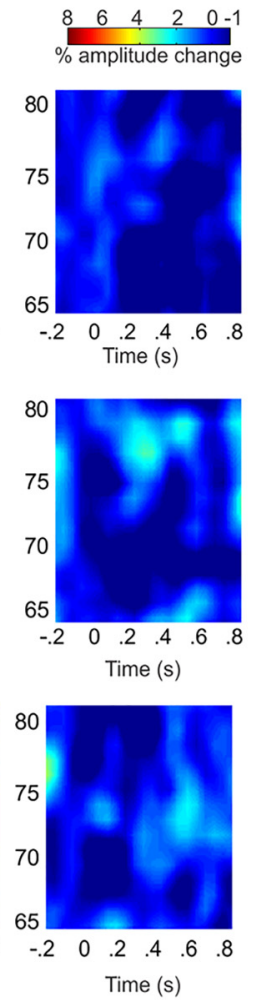

RAC
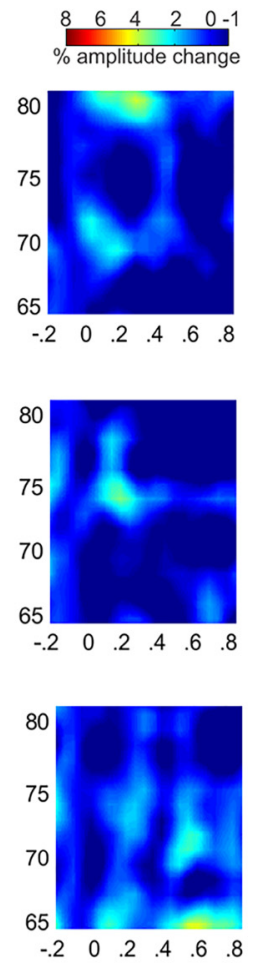

B

LAC

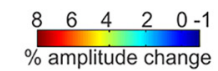

Native Deviant
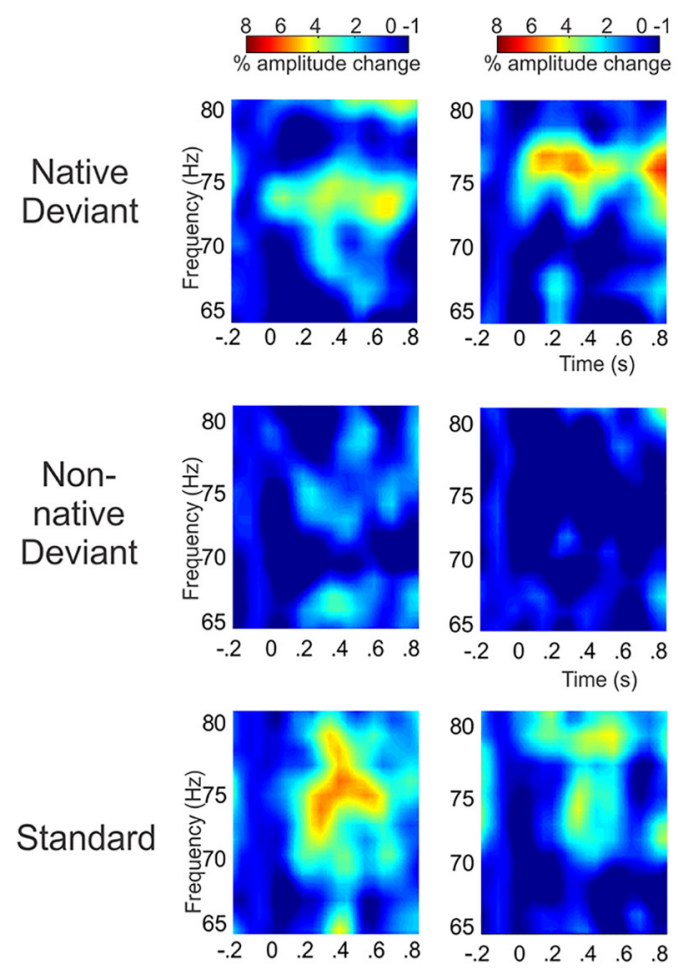

Non-

native Deviant

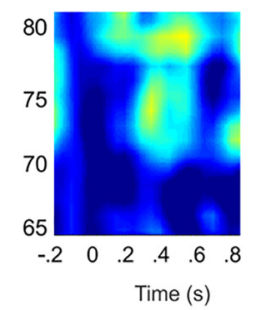

RAC
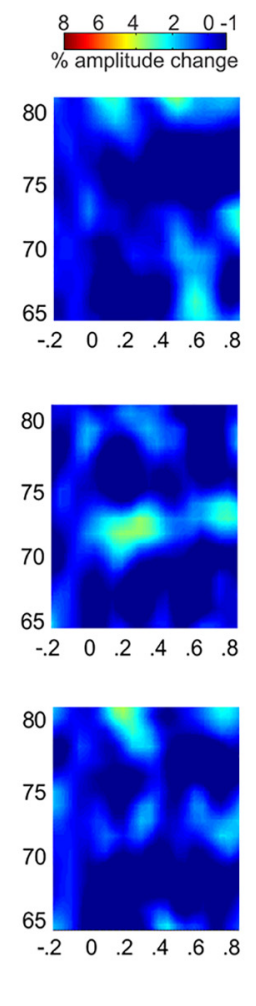

Figure 8. TSE grand average plots showing power for oscillations in the high- $\gamma$ range at LAC and RAC and in frontal cortex at the level of ACC. Power elicited is shown on the left at 6 months ( $\boldsymbol{A}$ ) and on the right at 12 months $(\boldsymbol{B})$. Top row represents TSE for ND. Middle row represents TSE for NND. Bottom row represents power elicited by the STD. At 6 months, a small burst of high- $\gamma$ power is seen in LAC for the STD. At 12 months, enhanced oscillatory activity in the high- $\gamma$ range is seen for both native syllables (ND and STD) in LAC and in ACC. Time is shown in seconds (s) on the $x$-axis and frequency in $\mathrm{Hz}$ on the $\mathrm{y}$-axis.

2003; Herrmann et al., 2004; Ribary, 2005; Buzsáki, 2006; Fan et al., 2007; Benasich et al., 2008; Uhlhaas et al., 2010; Gou et al., 2011) but may also play a role in coupling of remote cortical areas (Buzsáki and Schomburg, 2015). However, responses elicited in low- $\gamma(\sim 30-70 \mathrm{~Hz})$ may well be functionally different from those elicited in higher- $\gamma(>70 \mathrm{~Hz})$ ranges. Low- $\gamma$ oscillations appear to support object representations, temporal binding, arousal, attentional selection, and working memory (Engel and Singer, 2001; Uhlhaas et al., 2011). In contrast, high- $\gamma$ activity is a prominent characteristic of early sensory processing (Steinschneider et al., 2008) and may index cortical activation, given that larger high- $\gamma$, but not low- $\gamma$ responses correlate with increases in overall firing rates, particularly during attentional modulation (Crone et al., 2011; Ray and Maunsel, 2011). In humans, more consistent activations have been found in high- than in low- $\gamma$ ranges within auditory (Crone et al., 2006; Trautner et al., 2006), visual (Friedman-Hill et al., 2000; Frien et al., 2000), and motor domains (Miller et al., 2007). Indeed, whereas 6-month-old infants showed low- $\gamma$ enhancement to the ND in ACC, at 12 months, high- $\gamma$ activity was prominent for both native syllables in LAC and ACC. We suggest that the increases in high- $\gamma$ activity reflect the neural mechanism by which phonemic representations are established within auditory cortex. Simultaneous activation of presynaptic and postsynaptic neighboring neurons fosters plasticity (Hebb, 1949) by increasing synaptic strength between neurons that fire together, and thus is a useful mechanism to explain developmental processes (McClelland, 2006).

Further, cross-frequency synchrony of $\theta$ and $\gamma$ oscillations may mediate temporal integration of local neuronal activity into large-scale, coordinated, interregional networks, a crucial mechanism for cognitive, sensory, and perceptual processes (von Stein and Sarnthein, 2000; Canolty et al., 2006; Fujisawa and Buzsáki, 2011; Giraud and Poeppel, 2012; Lisman and Jensen, 2013; Doesburg et al., 2015). Interactions between ACC and auditory sensory regions have been reported in adults, with ACC activation relating to attentional modulation (Crottaz-Herbette and Menon, 2006), involuntary switching of attention (Waberski et al., 2001), and the orienting response to potentially significant auditory stimuli (Baudena et al., 1995). In consort with such studies, 6-month-old infants already demonstrate coordinated oscillatory activity across brain regions and frequency ranges. The enhanced low- $\gamma$ activity observed during the period in which infants are constructing their phonemic maps could be related to involuntary switching of attention toward an increasingly relevant stimulus change as they tune into their native language. At 12 months, infants showed stronger spectral and spatial responses that favored processing of native syllables (increases in high- $\gamma$ power in both ACC and LAC for both STD and ND stimuli). The fact that, at 12 months, no $\gamma$ enhancement was seen for the NND suggests that phonemic mapping may already be well established at 12 months and that $\gamma$ activity may indeed play an important role during infants' native language specialization (Peña et al., 2010; Ortiz-Mantilla et al., 2013).

Although EEG recordings do not have the precise anatomical specificity that ECoG recordings confer, the application of source-localization techniques allows a good estimate of the cortical areas contributing to the evoked responses. Notably, our results align with reports in adults using ECoG-array recordings 
in which processing of the temporal attributes of the VOT in native phonemes elicited a high- $\gamma$ response in PL-STG (Steinschneider et al., 2011; Mesgarani et al., 2014). However, as the participants in those studies were not presented with non-native phonemes, the authors could not ascertain whether the high- $\gamma$ response was due to general acoustic characteristics, or to "language-specific" phonemic differences. Although we acknowledge that it is more difficult to record $\gamma$ activity with scalprecorded EEG, due to the smaller amplitude characteristic of $\gamma$ activity and frequency similarities with electrical signatures for muscle activity (Crone et al., 2001; Sauseng and Klimesch, 2008), our findings are noteworthy. The fact that infants processing native and non-native VOT contrasts mounted a high- $\gamma$ response only for native syllables suggests that: (1) the equivalent current dipole model used was accurate enough to capture activity from/ close to the STG; (2) the high- $\gamma$ power exclusively elicited for native phonemes may represent STG specificity for the processing of language-specific phonemic information varying in VOT; and (3) the increased high- $\gamma$ response at 12 months to native phonemes may signal developmental progress in phonemic mapping, possibly representing the neural signature of phonemic perceptual narrowing.

\section{Lateralization of brain responses}

In adults, perception of ongoing speech is considered a multitime resolution process with cross-frequency interactions performed by both auditory cortices. Whereas synchronized oscillatory activity in the $\theta$ range is thought to resolve syllabic information, $\gamma$ oscillations may resolve segmental/phonemic information (Poeppel et al., 2008; Giraud and Poeppel, 2012). Similar to adults, syllable processing in infants is resolved in a multitime fashion through synchronized activity in low- and high-frequency ranges. However, our results are also in line with previous findings in infants (Dehaene-Lambertz et al., 2002; Gervain et al., 2008; Minagawa-Kawai el al., 2011; Mahmoudzadeh et al., 2013), suggesting that speech perception during the phonemic mapping period is left lateralized. It is known that both auditory cortices respond to temporal and spectral variation; however, it is the LAC, in particular, that appears to specialize in rapid temporal processing (Zatorre and Belin, 2001) and to support discrete phonological representations (Phillips et al., 2000). Our findings are consistent with this view, as infant processing in the $\theta$ range of rapid successive changes within both native and non-native syllables was predominantly left lateralized. Given that only processing of native information elicited a left-lateralized $\gamma$ response, we suggest that $\theta$ activity likely supports syllable processing at 6 and 12 months, whereas at 12 months, the switch from low to higher $\gamma$ activity signals a shift to preferential processing of native language.

In conclusion, the process of linguistic perceptual narrowing is critical to the establishment of fluent and efficient native language processing and constitutes a major task across the first year of life. The creation and tuning of the acoustic maps that support this process depend on ongoing neural plasticity and keen sensitivity to environmental cues; however, the details of how this process unfolds in the developing brain are still unclear. To our knowledge, this is the first time that the evolving time-frequency dynamics supporting phonemic perceptual narrowing have been closely examined over development. Our results provide a window into the dynamic and changing patterns that occur in neural mechanisms as language-specific phonemic mapping takes place and highlight the neural substrates of linguistic perceptual narrowing across the first year. Characterizing the normative neural mechanisms that support language acquisition is crucial to understanding how these processes might go awry in some children, and therefore will facilitate early screening for developmental language disorders and provide insights as to how one might alter the course of such impairments.

\section{References}

Baudena P, Halgren E, Heit G, Clarke JM (1995) Intracerebral potentials to rare target and distractor auditory and visual stimuli: III. Frontal cortex. Electroencephalogr Clin Neurophysiol 94:251-264. CrossRef Medline

Benasich AA, Gou Z, Choudhury N, Harris KD (2008) Early cognitive and language skills are linked to resting frontal gamma power across the first 3 years. Behav Brain Res 195:215-222. CrossRef Medline

Best CT, McRoberts GW, LaFleur R, Silver-Isenstadd J (1995) Divergent developmental patterns for infants' perception of two non-native consonant contrasts. Infant Behav Dev 18:339-350. CrossRef

Blumstein SE, Myers EB, Rissman J (2005) The perception of voice onset time: an fMRI investigation of phonetic category structure. J Cogn Neurosci 17:1353-1366. CrossRef Medline

Buonomano DV, Merzenich MM (1998) Cortical plasticity: from synapses to maps. Annu Rev Neurosci 21:149-186. CrossRef Medline

Buzsáki G (2006) Rhythms of the brain. New York: Oxford UP.

Buzsáki G, Schomburg EW (2015) What does gamma coherence tell us about inter-regional neural communication? Nat Neurosci 18:484-489. CrossRef Medline

Canolty RT, Edwards E, Dalal SS, Soltani M, Nagarajan SS, Kirsch HE, Berger MS, Barbaro NM, Knight RT (2006) High gamma power is phaselocked to theta oscillations in human neocortex. Science 313:1626-1628. CrossRef Medline

Chang EF, Rieger JW, Johnson K, Berger MS, Barbaro NM, Knight RT (2010) Categorical speech representation in human superior temporal gyrus. Nat Neurosci 13:1428-1432. CrossRef Medline

Cheour M, Ceponiene R, Lehtokoski A, Luuk A, Allik J, Alho K, Näätänen R (1998) Development of language-specific phoneme representations in the infant brain. Nat Neurosci 1:351-353. CrossRef Medline

Cosandier-Rimélé D, Merlet I, Badier JM, Chauvel P, Wendling F (2008) The neuronal sources of EEG: modeling of simultaneous scalp and intracerebral recordings in epilepsy. Neuroimage 42:135-146. CrossRef Medline

Cragg L, Kovacevic N, McIntosh AR, Poulsen C, Martinu K, Leonard G, Paus $\mathrm{T}$ (2011) Maturation of EEG power spectra in early adolescence: a longitudinal study. Dev Sci 14:935-943. CrossRef Medline

Crone NE, Boatman D, Gordon B, Hao L (2001) Induced electrocorticographic gamma activity during auditory perception. J Clin Neurophysiol 112:565-582. CrossRef Medline

Crone NE, Sinai A, Korzeniewska A (2006) High frequency gamma oscillations and human brain mapping with electrocorticography. In: Progress in brain research, Vol 159 (Neuper C, Klimesch W, eds), pp 275-294. Amsterdam: Elsevier Science.

Crone NE, Korzeniewska A, Franaszczuk PJ (2011) Cortical gamma responses: searching high and low. Int J Psychophysiol 79:9-15. CrossRef Medline

Crottaz-Herbette S, Menon V (2006) Where and when the anterior cingulate cortex modulates attentional response: combined fMRI and ERP evidence. J Cogn Neurosci 18:766-780. CrossRef Medline

David O, Maess B, Eckstein K, Friederici AD (2011) Dynamic causal modeling of subcortical connectivity of language. J Neurosci 31:2712-2717. CrossRef Medline

Dehaene-Lambertz G, Dehaene S, Hertz-Pannier L (2002) Functional neuroimaging of speech perception in infants. Science 298:2013-2015. CrossRef Medline

DeWitt I, Rauschecker JP (2012) Phoneme and word recognition in the auditory ventral stream. Proc Natl Acad Sci U S A 109:E505-E514. CrossRef Medline

Doesburg SM, Ward LM, Ribary U (2015) The alpha-theta-gamma (ATG) switch: toward unified principles of cortical processing. Curr Trends Neurol 9:1-12.

Edwards E, Soltani M, Kim W, Dalal SS, Nagarajan SS, Berger MS, Knight RT (2009) Comparison of time-frequency responses and the event-related potential to auditory speech stimuli in human cortex. J Neurophysiol 102:377-386. CrossRef Medline

Engel AK, Singer W (2001) Temporal binding and the neural correlates of sensory awareness. Trends Cogn Sci 5:16-25. CrossRef Medline

Fan J, Byrne J, Worden MS, Guise KG, McCandliss BD, Fossella J, Posner MI 
(2007) The relation of brain oscillations to attentional networks. J Neurosci 27:6197-6206. CrossRef Medline

Friederici AD, Friedrich M, Christophe A (2007) Brain responses in 4-month-old infants are already language specific. Curr Biol 17:12081211. CrossRef Medline

Friedman-Hill S, Maldonado PE, Gray CM (2000) Dynamics of striate cortical activity in the alert macaque: I. Incidence and stimulus dependence of gamma-band neuronal oscillations. Cereb Cortex 10:1105-1116. CrossRef Medline

Frien A, Eckhorn R, Bauer R, Woelbern T, Gabriel A (2000) Fast oscillations display sharper orientation tuning than slower components of the same recordings in striate cortex of the awake monkey. Eur J Neurosci 12:14531465. CrossRef Medline

Fujisawa S, Buzsáki G (2011) A $4 \mathrm{~Hz}$ oscillation adaptively synchronizes prefrontal, VTA, and hippocampal activities. Neuron 72:153-165. CrossRef Medline

Gervain J (2015) Plasticity in early language acquisition: the effects of prenatal and early childhood experience. Curr Opin Neurobiol 35:13-20. CrossRef Medline

Gervain J, Mehler J (2010) Speech perception and language acquisition in the first year of life. Annu Rev Psychol 61:191-218. CrossRef Medline

Gervain J, Macagno F, Cogoi S, Peña M, Mehler J (2008) The neonate brain detects speech structure. Proc Natl Acad Sci U S A 105:14222-14227. CrossRef Medline

Giraud AL, Poeppel D (2012) Cortical oscillations and speech processing: emerging computational principles and operations. Nat Neurosci 15: 511-517. CrossRef Medline

Gou Z, Choudhury N, Benasich AA (2011) Resting frontal gamma power at 16, 24 and 36 months predicts individual differences in language and cognition at 4 and 5 years. Behav Brain Res 220:263-270. CrossRef Medline

Hämäläinen JA, Ortiz-Mantilla S, Benasich AA (2011) Source localization of event-related potentials to pitch change mapped onto age-appropriate MRIs at 6 months of age. Neuroimage 54:1910-1918. CrossRef Medline

Hari R, Salmelin R (1997) Human cortical oscillations: a neuromagnetic view through the skull. Trends Neurosci 20:44-49. CrossRef Medline

Hayashi A, Tamekawa Y, Kiritani S (2001) Developmental change in auditory preferences for speech stimuli in Japanese infants. J Speech Lang Hear Res 44:1189-1200. CrossRef Medline

Hebb DO (1949) The organization of behavior: a neuropsychological theory. New York: Wiley.

Herrmann CS, Munk MH, Engel AK (2004) Cognitive functions of gammaband activity: memory match and utilization. Trends Cogn Sci 8:347-355. CrossRef Medline

Hickok G, Poeppel D (2000) Towards a functional neuroanatomy of speech perception. Trends Cogn Sci 4:131-138. CrossRef Medline

Hoechstetter K, Bornfleth H, Weckesser D, Ille N, Berg P, Scherg M (2004) BESA source coherence: a new method to study cortical oscillatory coupling. Brain Topogr 16:233-238. Medline

Hoechstetter K, Berg P, Scherg M (2010) BESA research tutorial 4: distributed source imaging. http://www.besa.de/downloads/training-material/tutorials/.

Hollingshead AB (1975) The four-factor index of social status. Department of Sociology, Yale University, New Haven.

Jansson-Verkasalo E, Ruusuvirta T, Huotilainen M, Alku P, Kushnerenko E, Suominen K, Rytky S, Luotonen M, Kaukola T, Tolonen U, Hallman M (2010) Atypical perceptual narrowing in prematurely born infants is associated with compromised language acquisition at 2 years of age. BMC Neurosci 11:88. CrossRef Medline

Jin Y, Díaz B, Colomer M, Sebastián-Gallés N (2014) Oscillation encoding of individual differences in speech perception. PLoS One 9:e100901. CrossRef Medline

Jusczyk PW (2002) How infants adapt speech-processing capacities to native-language structure. Curr Dir Psychol Sci 11:15-18. CrossRef

Ko D, Kwon S, Lee GT, Im CH, Kim KH, Jung KY (2012) Theta oscillation related to the auditory discrimination process in mismatch negativity: oddball versus control paradigm. J Clin Neurol 8:35-42. CrossRef Medline

Koroleva NV, Nebera SA, Gutnik IN (2002) Leading characteristics of maturity of the brain bioelectric activity in children 1-7 years of age. Hum Physiol 28:687-692. CrossRef Medline

Kriegeskorte N, Simmons WK, Bellgowan PS, Baker CI (2009) Circular analysis in systems neuroscience: the dangers of double dipping. Nat Neurosci 12:535-540. CrossRef Medline

Kuhl PK (2010) Brain mechanisms in early language acquisition. Neuron 67:713-727. CrossRef Medline

Kuhl PK, Williams KA, Lacerda F, Stevens KN, Lindblom B (1992) Linguistic experience alters phonetic perception in infants by 6 months of age. Science 255:606-608. CrossRef Medline

Kuhl PK, Conboy BT, Padden D, Nelson T, Pruitt J (2005) Early speech perception and later language development: implications for the "critical period." Lang Learn Dev 1:237-264.

Leonard MK, Chang EF (2014) Dynamic speech representations in the human temporal lobe. Trends Cogn Sci 18:472-479. CrossRef Medline

Lisker L, Abramson AS (1964) A cross-language study of voicing in initial stops: acoustical measurements. Word 20:384-422. CrossRef

Lisman JE, Jensen O (2013) The theta-gamma neural code. Neuron 77: 1002-1016. CrossRef Medline

Mahmoudzadeh M, Dehaene-Lambertz G, Fournier M, Kongolo G, Goudjil S, Dubois J, Grebe R, Wallois F (2013) Syllabic discrimination in premature human infants prior to complete formation of cortical layers. Proc Natl Acad Sci U S A 110:4846-4851. CrossRef Medline

Maris E, Oostenveld R (2007) Nonparametric statistical testing of EEG- and MEG-data. J Neurosci Methods 164:177-190. CrossRef Medline

Marshall PJ, Bar-Haim Y, Fox NA (2002) Development of the EEG from 5 months to 4 years of age. Clin Neurophysiol 113:1199-1208. CrossRef Medline

Maurer D, Werker JF (2014) Perceptual narrowing during infancy: a comparison of language and faces. Dev Psychobiol 56:154-178. CrossRef Medline

McClelland JL (2006) How far can you go with Hebbian learning, and when does it lead you astray? In: Processes of change in brain and cognitive development: attention and performance, Vol XXI (Munakata Y, Johnson $\mathrm{MH}$, eds), pp 33-69. Oxford: Oxford UP.

Mehler J, Jusczyk P, Lambertz G, Halsted N, Bertoncini J, Amiel-Tison C (1988) A precursor of language acquisition in young infants. Cognition 29:143-178. CrossRef Medline

Mesgarani N, David SV, Fritz JB, Shamma SA (2008) Phoneme representation and classification in primary auditory cortex. J Acoust Soc Am 123: 899-909. CrossRef Medline

Mesgarani N, Cheung C, Johnson K, Chang EF (2014) Phonetic feature encoding in human superior temporal gyrus. Science 343:1006-1010. CrossRef Medline

Michel CM, Murray MM, Lantz G, Gonzalez S, Spinelli L, Grave de Peralta R (2004) EEG source imaging. Clin Neurophysiol 115:2195-2222.

Miller KJ, Leuthardt EC, Schalk G, Rao RP, Anderson NR, Moran DW, Miller JW, Ojemann JG (2007) Spectral changes in cortical surface potentials during motor movement. J Neurosci 27:2424-2432. CrossRef Medline

Minagawa-Kawai Y, van der Lely H, Ramus F, Sato Y, Mazuka R, Dupoux E (2011) Optical brain imaging reveals general auditory and language- specific processing in early infant development. Cereb Cortex 21:254-261. CrossRef Medline

Moon C, Lagercrantz H, Kuhl PK (2013) Language experienced in utero affects vowel perception after birth: a two-country study. Acta Paediatr 102:156-160. CrossRef Medline

Musacchia G, Choudhury NA, Ortiz-Mantilla S, Realpe-Bonilla T, Roesler CP, Benasich AA (2013) Oscillatory support for rapid frequency change processing in infants. Neuropsychologia 51:2812-2824. CrossRef Medline

Musacchia G, Ortiz-Mantilla S, Realpe-Bonilla T, Roesler CP, Benasich AA (2015) Investigating infant auditory processing and event-related brain oscillations. J Vis Exp 101:e52420. Medline

Orekhova EV, Stroganova TA, Posikera IN, Elam M (2006) EEG theta rhythm in infants and preschool children. Clin Neurophysiol 117:10471062. CrossRef Medline

Ortiz-Mantilla S, Hämäläinen JA, Benasich AA (2012) Time course of ERP generators to syllables in infants: a source localization study using ageappropriate brain templates. Neuroimage 59:3275-3287. CrossRef Medline

Ortiz-Mantilla S, Hämäläinen JA, Musacchia G, Benasich AA (2013) Enhancement of gamma oscillations indicates preferential processing of native over foreign contrasts in infants. J Neurosci 33:18746-18754. CrossRef Medline

Peña M, Pittaluga E, Mehler J (2010) Language acquisition in premature 
and full-term infants. Proc Natl Acad Sci U S A 107:3823-3828. CrossRef Medline

Phillips C, Pellathy T, Marantz A, Yellin E, Wexler K, Poeppel D, McGinnis M, Roberts T (2000) Auditory cortex accesses phonological categories: an MEG mismatch study. J Cogn Neurosci 12:1038-1055. CrossRef Medline

Poeppel D, Idsardi WJ, van Wassenhove V (2008) Speech perception at the interface at neurobiology and linguistic. Philos Trans R Soc Lond B Biol Sci 363:1071-1086. CrossRef Medline

Pons F, Lewkowicz DJ, Soto-Faraco S, Sebastián-Gallés N (2009) Narrowing of intersensory speech perception in infancy. Proc Natl Acad Sci U S A 106:10598-10602. CrossRef Medline

Ponton C, Eggermont JJ, Khosla D, Kwong B, Don M (2002) Maturation of human central auditory system activity: separating auditory evoked potentials by dipole source modeling. Clin Neurophysiol 113:407-420. CrossRef Medline

Raschle N, Zuk J, Ortiz-Mantilla S, Sliva DD, Franceschi A, Grant PE, Benasich AA, Gaab N (2012) Pediatric neuroimaging in early childhood and infancy: challenges and practical guidelines. Ann N Y Acad Sci 1252:4350. CrossRef Medline

Ray S, Maunsell JH (2011) Different origins of gamma rhythm and highgamma activity in macaque visual cortex. PLoS Biol 9:e100610. CrossRef Medline

Ribary U (2005) Dynamics of thalamo-cortical network oscillations and human perception. Prog Brain Res 150:127-142. CrossRef Medline

Rivera-Gaxiola M, Silva-Pereyra J, Kuhl PK (2005) Brain potentials to native and non-native speech contrasts in 7- and 11-month-old American infants. Dev Sci 8:162-172. CrossRef Medline

Rivera-Gaxiola M, Silva-Pereyra J, Klarman L, Garcia-Sierra A, Lara-Ayala L, Cadena-Salazar C, Kuhl P (2007) Principal component analyses and scalp distribution of the auditory P150-250 and N250-550 to speech contrasts in Mexican and American infants. Dev Neuropsychol 31:363378. CrossRef Medline

Rivera-Gaxiola M, Garcia-Sierra A, Lara-Ayala L, Cadena C, JacksonMaldonado D, Kuhl PK (2012) Event-related potentials to an English/ Spanish syllabic contrasts in Mexican 10-13-month-old infants. ISRN Neurol 2012:702986. CrossRef Medline

Saby JN, Marshall PJ (2012) The utility of EEG band power analysis in the study of infancy and early childhood. Dev Neuropsychol 37:253-273. CrossRef Medline

Sauseng P, Klimesch W (2008) What does phase information of oscillatory brain activity tell us about cognitive processes? J Neurosci Biobehav Rev 32:1001-1013. CrossRef Medline

Scherg M, Von Cramon D (1985) Two bilateral sources of the late AEP as identified by a spatio-temporal dipole model. Electroencephalogr Clin Neurophysiol 62:32-44. CrossRef Medline

Scherg M, Berg P, Hoechstetter K (2010a) BESA research tutorial 2: EEG-fMRI coregistration, preprocessing, ERP and source analysis. http://www.besa.de/downloads/training-material/tutorials/.

Scherg M, Berg P, Hoechstetter K (2010b) BESA research tutorial 6: Timefrequency analysis and source coherence. http://www.besa.de/downloads/training-material/tutorials/.

Shafer VL, Yu YH, Datta H (2011) The development of English vowel perception in monolingual and bilingual infants: neurophysiological correlates. J Phon 39:527-545. CrossRef Medline

Steinschneider M, Volkov IO, Fishman YI, Oya H, Arezzo JC, Howard MA 3rd (2005) Intracortical responses in human and monkey auditory cortex support a temporal processing mechanisms for encoding of the voice onset time phonetic parameter. Cereb Cortex 15:170-186. CrossRef Medline

Steinschneider M, Fishman YI, Arezzo JC (2008) Spectrotemporal analysis of evoked and induced electroencephalographic responses in primary auditory cortex (A1) of the awake monkey. Cereb Cortex 18:610-625. CrossRef Medline

Steinschneider M, Nourski KV, Kawasaki H, Oya H, Brugge JF, Howard MA 3rd (2011) Intracranial study of speech-elicited activity on the human posterolateral superior temporal gyrus. Cereb Cortex 21:2332-2347. CrossRef Medline

Strange W (2011) Automatic selective perception (ASP) of first and second language speech: a working model. J Phon 39:456-466. CrossRef

Tallon-Baudry C, Bertrand O (1999) Oscillatory gamma activity in humans and its role in object representation. Trends Cogn Sci 3:151-162. CrossRef Medline

Tallon-Baudry C, Bertrand O, Delpuech C, Pernier J (1996) Stimulus specificity of phase-locked and non-phase locked $40 \mathrm{~Hz}$ visual responses in humans. J Neurosci 16:4240-4249. Medline

Trautner P, Rosburg T, Dietl T, Fell J, Korzyukov OA, Kurthen M, Schaller C, Elger CE, Boutros NN (2006) Sensory gating of auditory evoked and induced gamma band activity in intracranial recordings. Neuroimage 32:790-798. CrossRef Medline

Tsao FM, Liu HM, Kuhl PK (2006) Perception of native and non-native affricative-fricative contrasts: cross-language tests on adults and infants. J Acoust Soc Am 120:2285-2294. CrossRef Medline

Tsuji S, Cristia A (2014) Perceptual attunement in vowels: a meta-analysis. Dev Psychobiol 56:179-191. CrossRef Medline

Uhlhaas PJ, Roux F, Rodriguez E, Rotarska-Jagiela A, Singer W (2010) Neural synchrony and the development of cortical networks. Trends Cogn Sci 14:72-80. CrossRef Medline

Uhlhaas PJ, Pipa G, Neuenschwander S, Wibral M, Singer W (2011) A new look at gamma? High- $(>60 \mathrm{~Hz})$ gamma-band activity in cortical networks: function, mechanisms and impairment. Prog Biophys Mol Biol 105:14-28. CrossRef Medline

von Stein A, Sarnthein J (2000) Different frequencies for different scales of cortical integration: from local gamma to long-range alpha/theta synchronization. Int J Psychophysiol 38:301-313. CrossRef Medline

Waberski TD, Kreitschmann-Andermahr I, Kawohl W, Darvas F, Ryang Y, Rodewald M, Gobbelé R, Buchner H (2001) Spatio-temporal source imaging reveals subcomponents of the human auditory mismatch negativity in the cingulum and right inferior temporal gyrus. Neurosci Lett 308:107110. CrossRef Medline

Wang C, Ulbert I, Schomer DL, Marinkovic K, Halgren E (2005) Responses of human anterior cingulate cortex microdomains to error detection, conflict monitoring, stimulus-response mapping, familiarity, and orienting. J Neurosci 25:604-613. CrossRef Medline

Wang XJ (2010) Neurophysiological and computational principles of cortical rhythms in cognition. Physiol Rev 90:1195-1268. CrossRef Medline

Ward LM (2003) Synchronous neural oscillations and cognitive processes. Trends Cogn Sci 7:553-559. CrossRef Medline

Werker JF, Tees RC (2005) Speech perception as a window for understanding plasticity and commitment in language systems of the brain. Dev Psychobiol 46:233-251. CrossRef Medline

Werker JF, Yeung HH, Yoshida KA (2012) How do infants become experts at native-speech perception? Curr Dir Psychol Sci 21:221-226. CrossRef

Zatorre RJ, Belin P (2001) Spectral and temporal processing in human auditory cortex. Cereb Cortex 11:946-953. CrossRef Medline 